\title{
The distant moral agent
}

\author{
Tom Andreassen
}

Department of Philosophy and Religious Studies, NTNU Norwegian University of Science and Technology, tom.andreassen@ntnu.no

DOI: http://dx.doi.org/10.5324/eip.v11i2.1988

(cc)BY
Attribution 4.0 International License, which permits unrestricted use, distribution, and
reproduction in any medium, provided the original author and source are credited.

Among the defining characteristics of moral cosmopolitanism are the convictions that personal relations, like membership in social or political organizations from local communities to nation-states are insignificant for moral agents in determining their scope of concern. The moral scope is unlimited and moral duties reach globally. Following up on observations made by Onora O'Neill and others, I argue that Peter Singer's model of an expanding circle of moral concern needs a complementary tool to allocate duties. That tool can be found by supplementing the agent-centered perspective of the model with a regard for the social and institutional circles encompassing right holders. Instead of focusing on the duty holder, I suggest that the cosmopolitan's "ultimate unit of moral concern" - here, the claim holder and the perspective from her or his position - is methodologically made the focus when investigating moral duties. In this article, Singer's cosmopolitan model is kept, but turned around to serve as a rights-based approach for allocating duties. Methodologically, what needs to be examined is whether the scope of legitimate moral claims expands from the agent for the same reasons that the circle of moral concern expands from Singer's agent. The reversed model is then used to discuss the ethical issue - raised most prominently perhaps by Iris Marion Young, David Miller and also Onora O'Neill - of how to identify agents that could reasonably be said to have duties towards troubled or needy people far away, whether that agent be oneself or others.

Keywords: cosmopolitanism, global justice, moral claims, human rights, Peter Singer

\section{Introduction}

In the debate on how to deal with problems occurring far away from home, much attention has been devoted to questions about the duties of moral agents. The agents in question are thought to be more affluent than the victims, and they are positioned at such a large geographical distance that few, if any, social connections seem to exist between agents and victims. Not even our current global communication structure has reduced the social distance between people to an extent that truly has the potential to close the economic gap (or the differences in access to education; healthcare; personal security and more).

Within the particular debate on the possible obligations towards needy people far away, the preoccupation with moral duties has overshadowed questions about their 
rights and particularly about the scope of these rights. The perspective adopted here does not belong to the moral agent or the duty holder. It is instead informed precisely by the right-holder perspective - the person at the other end, so to speak. I argue that the methodological shift involved in changing the focus from the moral agent to the holder of legitimate moral claims better enables the identification of duty holders in any given case.

Singer provides one such paradigmatic case to consider in his much-commented 1972 article "Famine, Affluence, and Morality," in which he introduced the imagined example of a man witnessing a child, a stranger to him, about to drown in a small pond. The pond is just deep enough to be life threatening to the child, but it is shallow enough for the man to be able to wade out and rescue the child, although it would ruin his suit in the process. The ethical principle Singer discusses through this case is this: "If it is in our power to prevent something bad from happening, without thereby sacrificing anything of comparable moral importance, we ought, morally, to do it." 1 Finally, he assumes that "suffering and death from lack of food, shelter, and medical care are bad." 2

In his discussion he notes two crucial implications of the ethical principle. First, it is valid regardless of distances. Second, the principle does not distinguish between situations where the agent is the only one in a position to act and situations with millions of other agent candidates. It is the first of these two implications that most concerns us here. One would wish that Singer said more about its justification. However, he merely states that it must follow from any principle of impartiality, universalizability, or equality and that there is not much need to add to this. ${ }^{3}$

If we turn to his later work, we find justificatory arguments nevertheless. Leaving aside his preoccupation with biological development and his analogy (or even stronger connection) with the development of rationality, what he says about rationality itself is pertinent to his view on impartiality. Concerning equal consideration of interests between several persons, including oneself, he states that rationality enables us to take the broader perspective. This perspective informs us that "our own interests are no more important than the interests of others[.]." Hence, rationality itself excludes the significance of distance between people.

If we acknowledge the duty to sacrifice the suit to save the child's life, then Singer invites us to consider what difference it would make, if any, were the pond situation to occur at a distance from the agent. The distance to consider is great enough to exclude witnessing the child in peril first hand. Thus the agent has only second-hand information of the child's situation, let us say from a radio report.

The configuration of Singer's initial case is quite basic but very effective. There are two agents: the man in a position to help - whom we may call the moral agent, and the child-in-pond, whom we can call the victim (of circumstance). This basic configuration, however, seems to include two key approaches, not only one. The first approach asks, as Singer does, about the scope of duties for the agent in question. Taking this approach, one could or should ask whether the scope of duties covers strangers and if so, if it also covers geographically distant strangers.

As noted above, the second approach investigates not the scope of duties, but the scope of the victim's moral claims. What morally valid claims could she make on the stranger? And what morally valid claims - if any - would apply if her stranger were located in some distant location?

We thus have two approaches corresponding to the basic configuration of Singer's example. They are quite different in method, and possibly in ethical 
orientation as well: the duty-based approach and the claim-based approach. An indication that the most common perspective chooses to focus on the duty bearer, and not the claim holder, can be found in the familiarity with which we speak of misery and victims of poverty that are far away. ${ }^{5}$

The other angle, explored here, implies the considerably less familiar perspective of distant moral agents. From a cosmopolitan perspective that has no privileged center of attention, however, this opposite angle should not be foreign.

In the first instance, the perspective clearly belongs to the duty bearer. From this perspective, the victim is in a distant position. The second, opposite angle views the moral agent from the victim's perspective. Instead of exploring duties independently of whether or not any misfortune exists, the victim-centered angle explores duties in relation to actual misfortune. ${ }^{6}$ This perspective overlooks moral agents near and far. The aim of making this perspectival shift ${ }^{7}$ is to see what implications it might have for ethical discussions of persons near and dear to the claim holder, and not necessarily to all duty bearers.

The argument presented here is methodological rather than normative, and it is not particularly directed against Singer. It is normatively neutral in the sense that it applies to separate normative theories irrespective of their divergences. Deontological and consequential theories - to take two broad outlooks - offer mutually conflicting foundations for moral duties. The question of assigning duties in particular circumstances to particular agents can be treated separately and regardless of what foundation they are based on.

Important to note is that the issue of assigning normative duties requires one to establish the scope of the duties, i.e. to determine how far an individual's responsibilities go, however they are justified. Assigning normative duties also concerns how to differentiate between duties within their scope, to prioritize between tasks whenever they cannot be dealt with concurrently. Both issues are ones that universalist normative ethics does not inherently address.

However, cosmopolitan ethics, inspired by universalist ideas, may still represent a standpoint on these issues. To consider this possibility, we should first distinguish between universalist and cosmopolitan ethics. Roughly, we can say that only the latter notion carries a geographical component. Universalism, on the other hand, is the position that stands in opposition to value relativism. It concerns the validity of arguments, rather than the number of persons subscribing to it. With this distinction in place, we may determine whether Singer's model of an expanding circle of moral concern falls under one of the two descriptions or both. Since it clearly concerns distance I treat Singer's example as a cosmopolitan model. A positive determination of cosmopolitanism, consistent with Singer's model, follows below.

Author-reader relations in the literature may to a large extent explain why we are so much more familiar with the concept of distant claim holders than distant moral agents. Authors tend to address a global north audience, and then their localization of the two agents in the basic configuration follows from this.

It is not the case, however, that cosmopolitans are alone in their preoccupation with the moral scope of duties as compared to the weight that is given to moral claims or rights and their scope. Their critics follow suit, as it turns out. Thus communitarian critics have also argued for stronger duties towards those persons near you than the duties we may also have toward distant strangers. The focus has largely been on the moral agent and his or her duties towards others when they are 
strangers, and not on the victim of poverty (or other misfortunes) or on individuals who are obliged to act on behalf of the victim.

At least methodologically, a shift of focus from duty bearers to claim holders is an underexplored option in this particular field of ethical investigation, and this is a good reason for choosing to explore further the claim-based view and to apply it in the global justice debate. The assumption of this essay is that central questions associated with the problem of distance in ethics will turn out to be more manageable in a methodological perspective from claim holders.

To be sure, an ethics grounded in claims or rights is not novel in itself for anyone acquainted with Kantian ethics or more recent human rights-based ethics. I should therefore stress again that it is in the particular debate on what Frances Kamm has framed the problem of distance in morality ${ }^{8}$ that a claim-based perspective is rare to see. This also partly applies to discussions on global justice more generally, which has been distinctly influenced by cosmopolitan thought and predominantly concerned with negative (Thomas Pogge) or positive duties (Singer). ${ }^{9}$

It has been argued that Singer's child-in-pond example cannot deliver solid premises for the debate on problems far away, because it does not cover the contingencies involved in real-life situations of this sort. David Miller has objected that Singer says little about how obligations are to be assigned among many aidgiving candidates. ${ }^{10}$ Miller states that a suggestion on how to differentiate between multiple candidates would have provided the necessary guidance in thinking about global poverty. Kamm has made similar arguments against Singer on this point. ${ }^{11}$

Their substantial critique of his example is not applicable to the reversed use of Singer's model. The criticism pertains to the expanding scope of an agent's moral duties. Expanding, alternatively, the scope of the validity of moral claims can proceed because it does not identify duties at all. Instead, it identifies agents one by one, or group by group, as the circle of legitimate moral claims expands. Even though the model is the same, we see here that the use is quite different. In Singer's initial use of it, the model adds instances of moral concern (people, surely) for one and the same moral agent. In the reversed use of the model, the number of agents increases with the expanding circle, but the instance of concern remains one and the same.

Singer regards his model as ecumenical, meaning that it does not determine the normative basis for duty. He presents it as a model that is applicable for consequence ethics and deontology alike. The same holds for the reversed use, whereby the model does not provide a normative solution to the foundation of obligation.

The configuration of the model works well for my case in highlighting the two key approaches, which address the duties of the moral agent and the claims of the victim, respectively. In short, the configuration deals with both parties, whether they involve one or many individuals on either side.

Singer's model is described in more detail in his work, The Expanding Circle. ${ }^{12}$ Again, my use of the Singerian circle here has a methodological purpose. His model can be used to explore the claim-centered view. In doing this we replace the moral agent in the center, and into this center position we place the claim holder.

At least in some basic sense this seems a sound thing to do, given the condition that the concern for the victim in the basic configuration must, for any credible moral theory, outweigh the concern for the moral agent. The shift of perspective would imply that the moral agent asks what needs to be done and who should do it 
instead of asking what should I do about it - the latter being the self-centered question (cf. the expanding circle around the agent). ${ }^{13}$

\section{I}

Mass poverty as a result of inefficient or indifferent international policies, as well as poor domestic governance, are well-established drivers for widespread misery in various shapes and forms, including undernourishment, lack of access to essential medicines, and child mortality. ${ }^{14}$ Global justice theorists, like Thomas Pogge, Peter Singer and several others rightly sound the alarm about the scope and perseverance of the misery and point to everyone's duty to eradicate it.

In order to discuss how the duty can be distributed among all, I first address the more general problem of what obligations, if any, individuals living in relatively affluent regions of the world have towards people living under much less favorable conditions, often in distant regions as seen from the affluent regions. More specifically, the paper addresses the issue of basic rights, such as the right to basic healthcare, if there is such a right. My assumption is, following Onora O'Neill, ${ }^{15}$ that rights, in order to be effective in practical life and meaningful at the conceptual level, must be accompanied by obligations. This assumption points to the question of who bears the moral obligations that come with basic moral rights.

In the broad scope of deontological or utilitarian theories, guidance is provided on why every rational being has moral duties towards other rational and sentient beings and why any given moral agent has a duty to support rules or perform actions that promote the best outcome in terms of welfare for anyone affected. As pointed out by Richard Ashcroft, however: “'moral' theories (such as utilitarian theory, or natural rights theories such as Lockean theory or modern human rights theories) are less illuminating, in that they fail to construct compelling perfect obligations lying with specific agents." ${ }^{16}$ By perfect obligations, Ashcroft connects to the Kantian notion of perfect duties and thus takes them to be non-contingent. Distance or personal ties do not influence their strength and relevance. A perfect obligation will imply, he holds, "a specific duty to assist"17 for any particular agent. In Iris Young's treatment of the issue, she asks how we are to "conceptualize responsibility for producing and rectifying structural injustice." ${ }^{18}$ Her case concerns the inhumane working conditions in many sweatshops in low-cost countries, where conditions are such that whenever we hear and read about them we think somebody ought to do something about them. She says her question on injustice and responsibility involves a puzzle "because standard models of responsibility in moral and legal theory do not supply a satisfactory answer". ${ }^{19}$

The types of moral theories Young discusses are the cosmopolitan view on the one hand and state-centered views on the other. The refusal to acknowledge any moral significance of geopolitical borders between people, central to the cosmopolitan view, seems a promising conceptual framework for taking responsibility for distant regions. This framework first of all includes people far away in its scope of moral concern, and thereby also makes it reasonable to investigate criteria for assigning obligations toward people, irrespective of where they live or how far away they are from the moral agent. A statist view seems to have a comparatively harder task in justifying such obligations, or indeed to recognize them at all. 
Granted, many situations exist where it is reasonable to see severe deprivation in one part of the world as a matter of moral concern, perhaps implying duties for comparable privileged people at safe distance. Even so, convincing criteria for identifying responsible agents are needed. Young discusses some such proposed criteria, and I shall present her position, but first I want to make a few remarks on what I will not include in this presentation.

I will not speak directly on distributive justice in the following, nor about distribution of goods like essential medicines or socio-economic distribution in general. The issue here is instead the distribution of duties, so to speak, or better, the identification of responsible agents at the foundational level, which should in turn, and ideally, inform theory on those other distributive issues. The methodological approach I consider is to investigate in moral and political detail what moral claims or corresponding political rights people might reasonably be said to have or be entitled to from distant moral agents. ${ }^{20}$ These moral claims are assumed foundational and in fact not distributed. I will then proceed by making clear two distinctions that underlie the following discussion.

II

First, in taking up Young's discussion of cosmopolitanism I should make clear that I will be primarily concerned with moral cosmopolitanism, as distinct from legal or political cosmopolitanism. Adopting Pogge's distinction, ${ }^{21}$ legal cosmopolitanism is the ideal that all persons have equal rights under a shared political and legal system. Moral cosmopolitanism, on the other hand, merely states that all persons are morally related whether or not they belong to the same political unity, and that the relationship commands equal moral concern among everyone. Political units, as well as geographical proximity and cultural affinities, are morally insignificant according to this view.

Second, moral cosmopolitanism has three characterizing dimensions, pointed out by Pogge (2002:175) and slightly reformulated here.

1) Units of concern. The ultimate unit of moral concern is the individual person.

2) Unlimited scope. All persons count equally irrespective of physical distance, rank, ethnicity, gender, religion or any other personal or cultural characteristic.

3) Universal pertinence. The concern is equally distributed among people. No one has reason to be less concerned.

The broad scope and pertinence central to the cosmopolitan outlook surely invites concern about how to identify particular agents for specific obligations, as expressed by Ashcroft and Young above. ${ }^{22}$ I shall discuss these two dimensions here and take up the first one about the unit of concern by returning to Singer's model below.

Regarding unlimited scope of moral concern, even granting that concern is equally distributed among all (i.e. accepting universal pertinence), the moral agent still wants to know where to discharge his duties. Even when accepting personal moral duty towards fellow human beings without discriminating between them, he needs to know this. The moral agent's own material and financial resources, and influence on institutions, only allow him to attend to a miniscule number of individuals if the effort is going to be effective. He therefore must discriminate among the candidates somehow, even if refusing to do so along lines of physical proximity, personal ties, cultural dispositions and so forth. 
The agent accepts that his duty reaches well beyond his local social environment comprising family, friends, neighbors, colleagues and co-nationals. Unless he finds a method of discriminating between them, duties towards everyone must be equally respected. The agent's efforts will not only fail to have the desired effect if he discharges his duty equally within the vast scope of concern, but at a practical level no one will benefit in a noteworthy manner.

At the conceptual level, if we consider the dictum often attributed to Kant that ought implies can, the aggregate duties cannot surpass the agent's capacity. Reminiscent of the Kantian dictum, Singer employs a principle of marginal utility within his argument of consequential ethics. It states that one is not required to contribute beyond the point at which one's own suffering surpasses the gains, or utility, received at the victim's end. ${ }^{23}$ This is where Singer's principle sets the limit of capacity. In applying it however, one person's duty towards each and every person within the set scope surely dissolves into an indistinguishable proportion. Putting it in slightly different terms, if the contribution is to have significance at all for everyone involved, the agent's suffering already surpasses the perceived total gains immensely.

The pertinence of the duty to aid is balanced by the principle of marginal utility, which is introduced to tell a person when he or she has contributed enough morally, even if it is insufficient in practical terms. If the scope of concern does not include a theory of distribution within it, not only the contribution seems to dissolve as a consequence, but with it the duty itself. From a utilitarian standpoint at least, there can be no personal duty to contribute insignificantly.

If, on the other hand, the duty is made contingent upon others also complying, then new questions arise (which will not be dealt with here) as to how the individual should act in relation to concerted efforts. I leave out this contingency in order to follow Singer's reasoning a little further, as he dismisses this contingency as a concern for individual choice, stating that "this can make no real difference to our moral obligations." 24

Utilitarian arguments applied by Singer and others that focus on the greatest gain in happiness or welfare, could point the moral agent toward people who are worst off. If the number of people falling under the agent's scope is limited, such as a local community, he might well be able to determine who is worst off. In this case, much of the conflict between utilitarian and communitarian theory would be resolved. And indeed, the communitarian could act from the utilitarian principle within the area of his concern. We should therefore take care to thoroughly distinguish between utilitarianism and cosmopolitanism in discussing moral scope.

But if the utilitarian also operates with a cosmopolitan scope, the advice to assist the worst off individual leads to an impractical task. The knowledge needed to identify the worst off individual or group of individuals in the global scope at any given time is beyond most agents. ${ }^{25}$ Most likely it is beyond any personal agent both for practical reasons and also for theoretical reasons regarding problems of uniform comparisons between persons and their sense of wellbeing.

If the utilitarian instead takes a practical approach and concentrates on cases for which he has personal information, the scope of concern dramatically narrows. Any criticism that he could have looked further and should have known better, would come not from utilitarianism itself, but from any theory with a broader outlook. A true cosmopolitan, whether a consequentialist or not, would perhaps have to rely on 
the knowledge of NGOs, like Oxfam or Doctors Without Borders, and trust them with her or his donation instead of deciding the matter herself.

I will make one final note here to underline the distinction between utilitarianism and cosmopolitanism, and to emphasize that one can discuss the one without making statements about the other. The issue is cosmopolitanism as it is understood by Singer himself when he says: "[I]n writing about the obligation to assist the world's poorest people, I want to reach people who are not utilitarians, so I don't rely on utilitarian premises for that argument." 26

In and of itself, cosmopolitanism merely defines the scope as global, and importantly, establishes that any one person within it might come to be one's responsibility. It establishes, as I understand it, that any reduction of this scope of concern is unreasonable. However, what I have tried to show is that cosmopolitanism is not a theory for assigning duties within the scope. The belief that it is such a theory might cause the confusion that one's aid effort should be distributed, pre-theoretically, to each and every victim of poverty or other misery within the scope. It confuses the scope of potential responsibility and actual responsibility.

My understanding of the cosmopolitan outlook then, allows that within it our duties are in principle of unlimited scope and universal pertinence, but that some legitimate criteria for discrimination exist in the scope dimension and that some division of moral labor must be tolerated on the pertinence dimension. In fact, several suggestions have been made, most of which connect duties with what might be summed up as causation of various degrees. I shall now look into how Young comments on this strategy. ${ }^{27}$

\section{III}

In her treatment of a causation criterion for establishing duties within what she terms the 'cosmopolitan-utilitarian model', Young highlights its prominent feature, as she sees it, of being a liability model. The types of theories she addresses are, unlike Singer's, cosmopolitan-oriented theories that include discrimination criteria. They are often, according to Young, based on some form of causal liability. She holds that this criteria type derives from legal reasoning, where the function is to establish guilt or blame for a harm being done. ${ }^{28}$ As an ethical model, she finds it insufficient for several reasons.

One reason is that in the current production and trade environment, the distance between the wrongdoer and the wronged party is often great. In a case like this, such as is exemplified by the sale of apparel in Western countries that is produced in lowcost Asian sweatshops, the causal connection from producer to consumer is so complex that the liability model becomes accordingly imprecise. ${ }^{29}$ In clear cases with one perpetrator, where the causal connection to the harmful effects is evident, the model has applicability. However, the past decades' globalization of trade and finance has resulted in an increasing number of cases of a very different nature. The "clear rules of evidence" (Young 2006:118), which are central to a liability model based on causation, has escalated the need for a supplementary theory as conditions have evolved.

I shall take up two more points from Young's list of why the liability model is not sufficient for allocating duties and agents. One is that the model, in her view, is 
unduly backward looking. The other point is that the model fails to motivate by its insistence on blame, instead of more mobilizing pronouncements.

It follows from the very structure of a model based on causality that it looks to the past in order to find what produced harm or injustice. The causes are, by the very temporality of causal relations, prior to the resulting harm. Thus, Young says that "[u]sually the purpose of assigning responsibility in terms of blame, fault, or liability, then, is to seek retribution or compensation for this past action" (2006:121). When conceptualizing structural injustice, she convincingly maintains that the concern must be to reform practices in a forward-looking way in order to stop systematic injustice from happening in the future.

The point has also been stressed by O'Neill, who suggests distinguishing sharply between practical questions about what to do on the one hand and retrospective questions about the proper response to failure on the other. ${ }^{30} \mathrm{O}$ 'Neill draws on Bernard Williams when she states: "Forward and backward looking ethical questions may seem inseparable if one takes a rather specific, complex and hostile view of obligations." The view she has in mind is one that Williams criticizes as "the morality system":

[It] is a way of looking at ethical requirements that links them closely to issues about blame and other retrospective attitudes. This way of looking at ethics deliberately lumps together forward-looking practical questions -'what ought I, or we, or this institution do?' and judgmental, retrospective questions - 'what view should we take of those who fail to do what they ought'? ${ }^{31}$

O'Neill takes this to be a conflation of responsibility and obligation, and argues that obligations to act shall not be based on responsibility for past actions.

It should be noted at this point that things might look different if one foresees harm coming from ongoing activities now. ${ }^{32}$ This would be precisely a forwardlooking perspective, and also a causal one. Cases in point are structural injustices where it is reasonable to expect that a certain activity produces harmful effects for people. Young acknowledges this and separates such cases from the model she criticizes. She does not give her reasons for this, but it is reasonable to assume that she views this forward-looking causation model as applicable only to fairly transparent cases where the causal events are evident and not of a complex nature, which often makes the model inapplicable in the retrospective cases. Young in fact embraces the forward-looking causation model, assuming a case is sufficiently transparent, and includes it in the model she herself suggests, the social connection model.

Since no harm is yet committed in the forward-looking perspective, guilt and blame aspects do not belong to it. This brings me to the last reason I want to include, that of motivation. Identification of agents based on blame might work counterproductively because, as Young observes, when people are assigned obligations in proportion to blame they tend to react defensively. This is not a moral argument, but a psychological one, and I take it that it rests on a fair observation. The defensive reaction is likely to lead to excuses, and the more complex the causal situation is, the more candidates for blame are indeed to be found.

With her social connection model, Young proposes a different approach for allocating duties. Her positive account of this model is, however, not as radically 
different from a causation theory as one might expect. In a defining line she explains that " $[\mathrm{t}]$ he 'social connection model' of responsibility says that all agents who contribute by their actions to the structural processes that produce injustice have responsibilities to work to remedy these injustices" (2006: 102-3). Within her model, she replaces the causal criteria for assignment of duty with other relations: power, privilege, interest and collective ability. The structural processes here are not exclusive to nation-states or other institutions, but tend to be oriented to a more social level. Their scope is however cosmopolitan, with an emphasis on duties that range from the duties of victims themselves (for example factory workers in sweatshops) to improving working conditions, all the way to buyers in foreign markets.

I believe that what she accomplishes by her duty-oriented connection model could also, and with greater precision and more stringency, be achieved through a methodological focus on moral claims or rights. I shall now develop the argument to this effect through a return to Singer's theory of the expanding circle.

\section{IV}

Singer's historically and rationally expanding circle of moral concern starts its movement at the closest range seen from the agent:

Ethical reasoning, once begun, pushes against our initially limited ethical horizons, leading us always toward a more universal point of view. Where does this process end? Taking the impartial element in ethical reasoning to its logical conclusion means, first, accepting that we ought to have equal concern for all human beings. ${ }^{33}$

And:

The circle of altruism has broadened from the family and tribe to the nation and race, and we are beginning to recognize that our obligations extend to all human beings. ${ }^{34}$

The circle thus starts at the family level. As it expands, it includes more and more people. We can fill in our own personal ties in a decreasing order of strength and see that friends, neighborhood people, colleagues and so forth are included in our circle of concern as the circle expands. Singer sees the expansion as driven by rationality itself, that the human capacity for reason prevails over time, and that the circle has just started its movement. ${ }^{35}$ In the center of the circle is one agent and it is this agent's moral concern that is expanding through this rational process. As we can see, the expansion does not stop until the circle includes all human beings.

Singer's argument is that there is no reason to stop the expansion, that the expansion is reasonable. I shall not argue against this, because it is precisely what makes his model cosmopolitan. I have chosen his model as an example of the scope I want to discuss because, as already noted, it is effective and made transparent by the illustration of the child-in-pond-situation. In other words, I cannot criticize his model for being cosmopolitan, since this is the property needed for the present discussion.

Instead, I would like to point to a fact that he leaves out of his picture by the very agent-centeredness of the model, namely that other people have circles too. Audun $\emptyset$ fsti has noted that 
[T] he centeredness and perspectivity of human existence cannot be overcome through universality in the sense of expansion and size. In an important sense it cannot and should not be overcome at all. What we have to see is rather that a system of concentric circles of concern is built up around any human being. And we are obliged to respect the circles of others. $^{36}$

I will argue, in line with Øfsti, that it is as reasonable to respect the narrower circles as it is to accept the expanding circle. This is the case when the narrower circles designate the recipient's scope of moral claims. I contend that Singer's agentcentered model cannot capture this, and therefore a method to find moral claims the basis for distribution of duties is lost. More precisely, I do not argue that expanding the agent's scope of moral concern is irrational, only that it is insufficient as a tool for assigning moral obligation, unless one also considers the recipient's social and institutional situation.

In the following section, I distinguish between moral concern and moral obligation by taking the sphere of moral concern to delimit the domain of possible moral obligations. The people included in the expanding sphere of concern are then the people to whom I can come to stand morally obligated, and we need to ask how I, as a moral agent, should deal with the social and institutional circle encompassing people. I would therefore argue that one must consider not only one, but two agent considerations. They correspond to Singer's basic configuration of two parties - the moral agent and the victim. One consideration is the moral agent's expanding circle of moral concern as viewed from inside, from the agent's own viewpoint. The other consideration also belongs to the agent. It regards the victim's circles, which are viewed from the outside. I shall try to determine their significance shortly.

In the introduction, the viewpoint from which I considered the basic ethical configuration belonged to neither the moral agent nor the victim. The issue there was how to theorize about their situation. It was observed that there are two parties involved and that many people choose to focus the theory on the moral agent. Now, in order to stay close to the duty-based theories coming out of this perspective, we shall stick with the moral agent's viewpoint.

Since the ultimate unit of moral concern within the cosmopolitan perspective is after all the individual person, it seems reasonable that the moral agent, also the cosmopolitan agent, takes the recipient's socio-political circles into consideration. The theoretical positions to which Singer's cosmopolitanism is an alternative (such as particularism and communitarianism) actually share Singer's agent-centered outlook. They differ mainly in that they draw the circles closer to the agent in order to allow preferential treatment of co-nationals, for example. The various positions essentially share the same perspective, where the vantage point is the agent. ${ }^{37}$ Moral agents are in turn portrayed as self-centered, however, to the extent that they fix their attention on their own duties. Andrew Kuper therefore holds, in the journal debate with Singer referred to above, that the debate is "couched in terms of an unhelpful binary opposition of 'self-ish' against 'self-less.' The whole debate is too narcissistic in its preoccupation with conscience and sacrifice." 38

To look at social and institutional circles from outside means that the relations in question are those of another person and not oneself. Two different ways of doing this appear to be available. First, one might approach the situation of another person through sympathy and empathy or second, through respect. The first method would imply trying to imagine what the recipient's social and institutional relations - 
circles, in Singer's terminology - look like from the inside. This is the familiar thought experiment of putting oneself in another person's shoes. Staying with the view from outside, however, we should not take this route but instead keep the outsider's position. From this viewpoint the circles present themselves as a matter to be respected or not. We may note that Young's theory of connectedness is not about sympathy, but of social connections established by interaction, with trade as a prominent example.

To take pause from the technical language of outside and inside considerations and social circles, let us consider two examples, one from the literature, the other from a possible neighborhood schoolyard situation. In writing about special obligations to family members, Williams has described an imagined case where several persons are in immediate danger and one of them is the agent's wife. There is also the premise familiar from such imagined cases that no possibility exists of rescuing more than one person. Williams makes the point that any plausible moral theory must accept the reason "it's my wife" for rescuing the wife. ${ }^{39}$

Paul Gomberg has commented that this answer is egoistic in contradistinction to an answer like "it's my group," which expresses a moral attitude - a parochial one. ${ }^{40}$ Williams forcefully argues that the agent has "one thought too many" if he reasons: The woman in peril is my wife "and that in situations of this kind it is permissible to save one's wife." 41 Williams' argument is existential, calling attention to the role of deep attachments. Without such attachments to other people, he argues, "allegiance to life itself" is at risk. He also includes adherence to impartial morality systems among the things that gives life the necessary "substance or conviction".

By the very existential merit of his argument we see, however, that the focus of attention rests clearly, even here, with the agent. Considering the wider body of Williams' work, it is the agent's life projects that are threatened by the prospect that his spouse is in danger. The moral issue is, according to Williams, that every person's life prospects have moral significance.

If we alternatively do not concentrate on the agent's duties and concerns but instead shift the attention toward the recipient, in this case the agent's wife, other moral issues surface. By shifting the perspective, the idea is accessed that she has more reason than the others at risk to think that she has been let down by the rescuer if he chooses some other person than her, say by flipping a coin. The circumstance that she has special claims on him is not captured by the agentcentered perspective evident in talk of preferential treatment of our own. It therefore also goes unobserved, as for Gomberg, that in rescuing his wife the agent acted on her moral claims towards him and that his act by that motivation was a moral act and not an egoistic one. If, hopefully, he also had strong feelings about his wife being in peril, they merely add affection to the deed. This affection hardly gives reason for moral frustration. On the contrary, it corresponds well with the existential qualities taken up by Williams.

By shifting the attention from the agent's duties and concerns to a consideration of the other parties' legitimate claims - and in the political realm, on their rights the agent in the example could realize that he had a particular obligation in this case. He could recognize this without the awkward support from one thought too many and furthermore without support from his own life projects.

In our next example we observe an imagined instance of human suffering, a malnourished child in the schoolyard. I cannot help noticing this shorter, thinner and paler boy every time I pass him en route to my office. As weeks and months 
pass with no signs that the boy's appearance of health is catching up with the other kids, my concern grows that he is not being properly cared for. I make some initial inquiries about his situation. I soon learn that he rarely brings food to eat at school like the other kids do, and that the word among the other children is that he is poor.

In approaching a case like this, we would quite likely and very reasonably start cautiously. We might seek circumstantial information about the victim's family situation, whether relatives know about the boy's condition or have had a chance to help, and if they have failed, whether other people or institutions should be informed. It should be noted that the caution demonstrated in this situation is not exercised in order to escape moral obligation, but rather to avoid conflicting ones. Caution is observed to respect other people's or institutions' obligations, by accepting their first-hand information and acknowledging the complexity of the situation and issues of time and organizational matters. Institutions that acknowledge a certain responsibility for their employees, students or others ask for just this kind of information to be reported on potential victims.

Every time we proceed cautiously in situations similar to this, our actions confirm our respect for other persons' social and institutional relations. The concerned attitude displayed here nevertheless testifies to the point that the scope of concern is not limited to family and friends, but can go further than that, indeed much further in cases where social and institutional relations break down.

Due to reasons of expansion, the moral agent's scope of concern is wide, and in principle unlimited. This is what Singer's model shows. How about the social circle around the recipient - can that circle be pushed outwards for the same reasons? The circles encompassing the recipient represent the social and institutional units towards which the person can direct legitimate moral claims. In this respect they are not actually "circles of concern" as Øfsti (pointedly) sees them in the context of the citation above. Here they are rather delimitations of legitimate moral claims.

Again, the moral agent is not at the epicenter of the social circles, but the recipient, or claim holder, is. This can be captured from outside, from the agent's position. The distinction to be made is one between the view from inside the Singerian circle of moral concern and the view from outside at other persons' circles. The first view, then, corresponds to the scope of concern and the second to the pertinence in my reformulation of Pogge's explication of the cosmopolitan outlook above. The moral agent is at the center of the view from inside, whereas the claim holder has this position in the agent's view from the outside. Even though we agree it is reasonable to expand the circle from the first perspective, as Singer holds, the other perspective finds that the social circle surrounding a person only expands when the original social surroundings fail, as in the schoolboy example. ${ }^{42}$

One might object at this point that a place for special obligations exists even within the agent-centered view, allowing for different roles as family member, neighbor, colleague and so forth. It might well be that such allowances could be admitted, without taking other persons' moral claims into view, but they would then come as exceptions to the general rule, or as in Robert Goodin's case, as derivatives of the general rule. ${ }^{43}$

What is worse is that a duty-based theory seems weaker than a theory grounded in claims or rights (corresponding to moral and legal cosmopolitanism, respectively). ${ }^{44}$ This is due to duty-based theories' dependence on agent surveillance and initiative. In claim-based theories, agents are instead picked out simply by the quality of being next in line. The securing of moral rights then, is determined by the 
bystander's reaction to being first in line to act on them, or to acknowledge the personal duty activated by being in this position.

The view from outside other persons' protective social shields provides the agent with a map, where the assignment of obligations is at least sketched out and shows which person or institution is to take over the case whenever a social shield fails. The perspective from duties does not provide this information as clearly or directly, because it has to rely on oft-contested assertions of cause and blame.

The perspective from other people's legitimate moral claims deals with the problem of dissolving duties. It is a view from a particular position in the world where circles of moral claims are being monitored. Thus, it is not a view from nowhere, informed but not concerned. ${ }^{45}$

The problem of universal rights is well known: if all circles but the most distant are to be removed, not from the agent, but from the holder of the rights, the position of the holder is less secure. ${ }^{46}$ The moral claims or legal rights meet with obligations in the nearest social or institutional body, respectively, as seen from the claim holder. Important to consider is that I might find myself repositioned by events from a position outside of the claim holder's social and legal situation to the innermost circle of a recipient far away. My repositioning might occur irrespective of any prior involvement in creating the circumstances that need to be addressed, as in the imagined case of the malnourished schoolboy above.

If the inquiry for circumstantial information about the child's social and institutional relations reveals that his family is dysfunctional, his relatives unaware, the kindergarten personnel not brave enough to report the case and the school's routines to deal with it deficient, we are likely to become more worried rather than less as we progressively uncover the facts. The sense of discomfort or alarm intensifies as we find that one social shield after another has failed. The sense and awareness of the stranger's unsupportable situation thus grows more personal for us instead of being peripheral within the general scope of concern. Short of developing a psychological argument for the case, I content myself with taking the imagined case to give intuitional support for the stringency of moral obligations outside the narrower scope of concern, even if there has been no prior involvement from the agent's side.

In the institutional realm, we might consider any case where agents create or contribute to an unlawful situation, through military operations for example, and thus fail to assume their responsibility for post-war security and (re)establishing institutions. The claim-based approach seems better equipped to identify agents for remedial responsibility, to borrow Miller's term, than the focus on duties alone can do. Bystander nations and regional organizations accepting the claim-based view would find that they could point to the perpetrator and his duties only for so long. They would then realize that the task falls upon them as neighbors, trading partners, allies, or co-members in regional organizations to meet - not out of good will but out of obligation - the moral claims for medicines, food and civilian security. The victims' claim cannot be derived from the duties of the perpetrator, because it has a wider reach. The order rather seems to be the opposite, that their claims activate obligations. When the first in line has failed in his obligation, the claim perspective would demand that the next in line is obligated to take over.

A person could also be positioned in the innermost circle of a recipient far away by being a member of an institution or corporation that has played a role in shaping the predicament of the remote person. An example of such involvement would be 
large-scale foreign aid, such as the aid delivered by many countries to Afghanistan in recent years. Another example would be Western states' responsibility after military operations, as in the security situation in Libya after the removal of the leadership there in 2011. Yet another example might be state-supported or state-operated foreign trade and commerce activities like oil production and mineral excavation. When an agent is repositioned to the inner circles of the claim holder by events of this sort, the stringency of the claims towards the relevant institution, in these cases my nation-state, will be of the highest order and thus far from dissolved.

A claim-based approach serves this end, I believe, by rejecting a system of different rationales for agency, where a rationale for the perpetrator will not be valid for the bystander. An altogether different rationale is required for the bystander, which is hard to accomplish without recourse to mere benevolence - an unsecure resource for the party who has been wronged or suffered a misfortune. A claim-based approach, rather than an exclusively agent-centered duty-based approach, can activate obligations also for bystanders, and indeed for local authorities as well.

\section{V}

To reiterate, the topic of this essay is methodological issues regarding the allocation of duties. I have defended the position that the sorting out of obligations and, correspondingly, the identification of duty holders are better served, or perhaps even made possible, by concentrating more on the claims of those harmed than on the duties of any individual person or institution operating with a global scope as his or her principal tool.

The view on allocation of duties that follows from the proposed reorienting of outlook is that no claim on the moral agent exists before the inner circles of the recipient have been tested and failed. Hence there are no duties to discharge before the expansion by failure of the claim holder's social circles. The claim holder's circles expand as those most closely connected to her or him fail in their obligation. The direction of the expansion in my reoriented view is toward the agent, rather than away from the moral agent, as in the expanding circle of moral scope. The circle closing in on the agent, so to speak, is the circle of other people's legitimate moral claims already covered by his concern. The claim holder's circles do not threaten to dissolve when they are being pushed outwards and towards the agent. The duty to assist following from the universal scope is a principled duty, activated by certain circumstances.

The two agent-perspectives combined - the agent's own moral concern and his regard for other persons' claims - activate his agency, so to speak. They differ from Young's model in that the duties are not always activated, even if the agent possesses the qualities of power, privilege and so forth, which are the triggers in her model. This is because the recipient may have legitimate claims on other, closer social or political units.

In a claim-based perspective, the moral agent is the distant other instead of the needy claim holder holding this position. The validity of the claim does not follow only from the recipient being drawn into the circle of the agent, or according to Singer, by expansion of the agent's circle to include the recipient within its domain. Moreover, it is the agent who finds himself within what has become the innermost circle of the recipient. This combined position of the agent is what validates the claim and correspondingly gives the duty its pertinence. 


\section{Acknowledgements}

The author wishes to thank the following for their much valued comments and suggestions. Henning Hahn; Bjørn Myskja; two anonymous reviewers for Nordic Journal of Applied Ethics; Per-Erling Movik; Morten Langfeldt Dahlback; the Global Justice Program at Yale University where I had the opportunity to present an early draft of the manuscript for discussion; and Shmuel Nili.

\section{Notes}

${ }^{1}$ (Singer 1972:231)

${ }^{2}$ (Singer 1972:231)

${ }^{3}$ (Singer 1972:232)

${ }^{4}$ (Singer 1981:111)

${ }^{5}$ Singer's model is but one example of this. Others are Thomas Pogge's arguments for global negative duties in Pogge (2002: 14f). The duties in question are justified with reference to causal factors, i.e. by placing responsibility with wrongdoers people and peoples whose former behavior has negatively impacted people or peoples elswhere; Goodin (1988) on special duties to family, friends and compatriots, central in the debate on communitarianism vs. universalism preceding the more recent debate on global justice; Barry (2005) on ethical responsibility for poverty far away based on "our" contribution to it; Brock (2008) on commitments and obligations. These are all prominent names in the global justice debate, and the premises for it (Goodin). This is the debate I discuss, and my claim that the duty holder perspective overshadows the victim perspective is meant to apply to this debate in particular not to ethics more generally.

${ }^{6}$ I do not differentiate between misfortunes that are caused by oneself or others and mere events, accidents, at this point. By misfortune I mean to refer to any situation where a person or a group of persons suffer from constant or sudden poverty, illness, oppression, lack of security or related deprivations. Below I take up the question of the moral significance, if any, of them being caused by oneself or not.

${ }^{7}$ Among prominent theorists that have opened the field I count Joel Feinberg and Ronald Dworkin (see literature references below).

${ }^{8}$ (Kamm 1999:177)

${ }^{9}$ (Pogge 2002) and (Singer 1981)

${ }^{10}$ (Miller 2007:234-5)

${ }^{11}$ (Kamm 1999)

${ }^{12}$ (Singer 1981)

${ }^{13}$ I realize that my phrasing of the moral agent as self-centered in Singer's original model might invite opposition. Still, I believe it is worthwhile pursuing this path to see if it works for a perspective from claim holders.

${ }^{14}$ For disturbing numbers, see Pogge (2010:11-12)

${ }^{15}$ (O’Neill 2005)

${ }^{16}$ (Ashcroft 2005:140), his italics.

${ }^{17}$ (Ashcroft 2005:126)

${ }^{18}$ (Young 2006:115)

${ }^{19}$ (Young 2006:115) 
${ }^{20}$ I separate moral claims from political rights here and in the following, seeing claims as holding between persons, and rights as regulating between persons and political institutions. I concern myself with moral claims in this essay.

${ }^{21}$ (Pogge 2002:175)

${ }^{22}$ They are not alone, of course. Much has been written on the issue over the last three decades or so by theorists like Thomas Nagel, Bernard Williams, Samuel Scheffler, Michael Walzer and many others. Mostly the discussion has revolved around the observed failure of the broad outlook to accommodate the intuitive appeal, pointed out by particularists and communitarianists, of special obligations to people close to you. The more recent debate regarding John Rawls's statist view in The Law of Peoples has carried the focus over to the realm of political institutions and global justice.

${ }^{23}$ (Singer 1972:234)

${ }^{24}$ (Singer 1972:233)

${ }^{25}$ Samuel Scheffler has referred to consequentialism's efforts to accommodate the information problem by "arguing back to a more conventional position" as its "well-known normative schizophrenia" in Scheffler (2001:42-3). His critique therefore presupposes that consequentialism comes with a (problematically) broad scope of moral concern, which might or might not be the case.

${ }^{26}$ See his journal debate with Andrew Kuper in Singer (2002b:127)

${ }^{27}$ For another critical, and more comprehensive, analysis of the relation ship between causation and moral duty, see Miller (2007) ch.4.

${ }^{28}$ See for example Barry (2005) for an example of this approach. My references to Young are throughout to Young (2006).

${ }^{29}$ For a similar concern, see Scheffler (2001) chap. 2.

${ }^{30}$ (O’Neill 2004:248)

${ }^{31}$ (O’Neill 2004:248). She is quoting Williams (1985; ch. 10).

${ }^{32}$ (Pogge 2002)

${ }^{33}$ (Singer 2011:119)

${ }^{34}$ (Singer 2011:120)

${ }^{35}$ (Singer 2011:113)

${ }^{36}$ (Øfsti 2002:280). Printed in Burckhart, H. und Gronke, H. (2002)

${ }^{37}$ I take Scheffler's view on "associative duties" to be another instance of this, for example through its reference to identity-forming membership in social groups (Scheffler 2001:57).

${ }^{38}$ (Kuper 2002:111)

${ }^{39}$ (Williams 1981:18)

${ }^{40}$ I borrow this point from Øfsti (2002:274).

${ }^{41}$ (Williams 1981:18)

${ }^{42}$ Even in a cosmopolitan "one polity" theory it would not be reasonable to assume that people have legitimate moral claims towards only one global institution. The necessary decentralization of functions and institutions could not ignore people's moral claims at various levels.

${ }^{43}$ (Goodin 1988). In Williams' case they would come as "one thought too many," as we have seen.

${ }^{44}$ In statist theories often based on Hobbes, like Thomas Nagel's in Nagel (2005), the argument is that there cannot be meaningful talk of rights unless there are duties in place to secure them. I assume the reversed statement is as reasonable, that unless there are people with rights there cannot be talk of duties. A logically related claim is 
made by Singer with regard to interests and equality: "If there are no beings with interests, the requirement that we treat all interests equally is entirely empty." See Singer (2011:106).

${ }^{45}$ Ref. Nagel (1986).

${ }^{46}$ This is the statist argument from Nagel and others.

\section{References}

Ashcroft R. E. (2005). Access to Essential Medicines: A Hobbesian Social Contract Approach. Developing World Bioethics vol 5, No 2. https://doi.org/10.1111/ j.1471-8847.2005.00108.x

Barry, C. (2005). Applying the Contribution Principle. Metaphilosophy Vol. 36, Nos. 1/2. https://doi.org/10.1111/j.1467-9973.2005.00363.x

Beitz, C. R. (1975). Justice and International Relations. In Pogge, TW \& Moellendorf, D (2008). First published in Philosophy and Public Affairs 4:4 (summer): $360-89$.

Burckhart, H. und Gronke, H. (2002). Philosophieren aus dem Diskurs. Beiträge zur Diskurspragmatik. Würzburg: Königshausen \& Neumann.

Goodin, R. E. (1988). What is So Special about Our Fellow Countrymen? Ethics, Vol. 98, No. 4. https://doi.org/10.1086/292998

Jamieson, D. (1999). Singer and his critics. Oxford: Blackwell. Reprinted 2000.

Kamm, F. M. (1999). Faminine Ethics: the Problem of Distance in Morality and Singer's Ethical Theory. In Jamieson D (1999), Singer and his critics.

Kuper, A. (2002). More Than Charity: Cosmopolitan Alternatives to the "Singer Solution". Ethics \& International Affairs 16, no. 2. https://doi.org/10.1111/ j.1747-7093.2002.tb00378.x

Miller, D. (2007). National Responsibility and Global Justice. New York: Oxford University Press. https://doi.org/10.1093/acprof:oso/9780199235056.001. 0001

Nagel, T. (1986). The View from Nowhere. New York: Oxford University Press.

Nagel, T. (2005). The Problem of Global Justice. Philosophy \& Public Affairs 33, no. 2. https://doi.org/10.1111/j.1088-4963.2005.00027.x

O'Neill, O. (2000). Bounds of Justice. Cambridge: Cambridge University Press. https://doi.org/10.1017/CBO9780511605734

O'Neill, O. (2004). Global Justice: Whose Obligations? In Chatterjee (2004).

O'Neill, O. (2005). The dark side of human rights. International Affairs 81, 2 . https://doi.org/10.1111/j.1468-2346.2005.00459.x

Pogge, T.W. \& Moellendorf, D. (2008). Global Justice: Seminal Essays. St. Paul: Paragon House.

Pogge, T. W. (2002). World Poverty and Human Rights. Oxford: Blackwell.

Pogge, T. W. (2010). Politics as Usual. Cambridge: Polity Press.

Satz, D. (2005). What Do We Owe the Global Poor? Ethics \& International Affairs Vol. 19, Issue 1, March 2005. https://doi.org/10.1111/j.17477093.2005.tb00489.x

Scheffler, S. (2001). Boundaries and Allegiances. Oxford: Oxford University Press.

Singer, P. (1972). Famine, Affluence, and Morality. Philosophy and Public Affairs, Vol. 1, No. 3

Singer, P. (1981). The Expanding Circle. New York: Farrar, Straus \& Giroux, 2011. 
Singer, P. (2002). Achieving the Best Outcome. Ethics \& International Affairs 16, no. 2. https://doi.org/10.1111/j.1747-7093.2002.tb00381.x

Williams, B. (1981). Moral Luck. Cambridge: Cambridge University Press, 1993. https://doi.org/10.1017/CBO9781139165860

Williams, B. (1985). Ethics and the Limits of Philosophy. London: Fontana Press, 1993.

Young, I. M. (2006). Responsibility and Global Justice: a Social Connection Model. Social Philosophy \& Policy vol. 23, Issue 1. https://doi.org/10.1017/ S0265052506060043

Øfsti, A. (2002). Solidarity, Egoism and Universalism. In Burckhart und Gronke (2002). Philosophieren aus dem Diskurs. Beiträge zur Diskurspragmatik. Würzburg: Königshausen \& Neumann, pp. 272-294. 